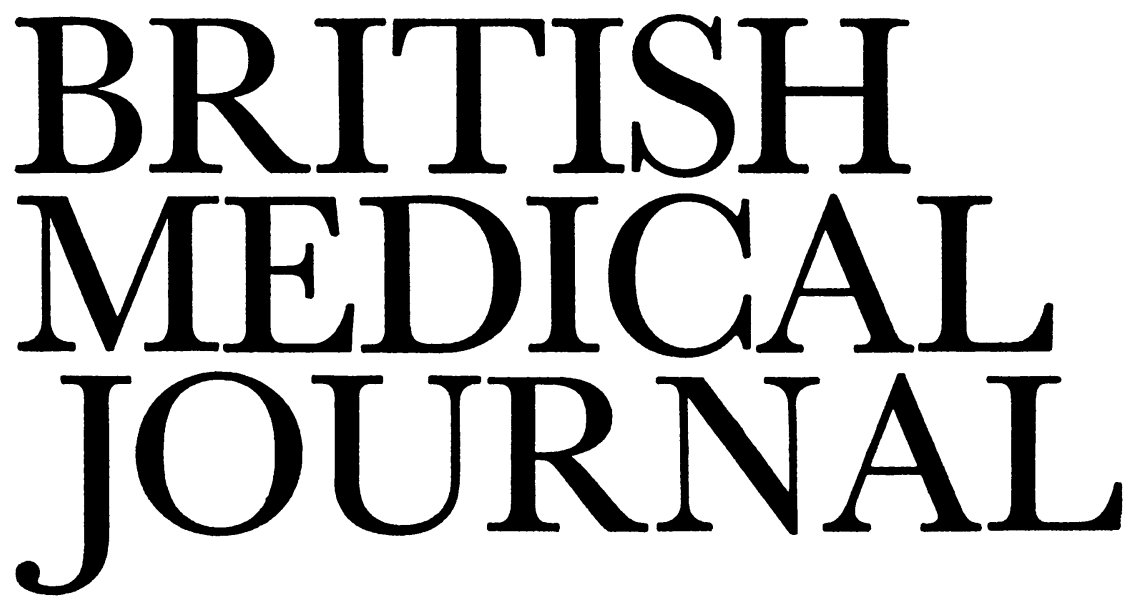

\title{
Total Replacement of the Hip
}

J. Charnley ${ }^{1}$ has recently published the first major longterm review of total replacement hip arthroplasty and has been able to report sustained excellence of results four to seven years after the operation. Total replacement of the hip is emerging as one of the most important developments of modern orthopaedics.

The severe disability that may arise from osteoarthritis of the hip has been a strong stimulus to the search for a reliable arthroplasty. The excision of the hip joint associated with G. R. Girdlestone ${ }^{2}$ was an early and still important contribution, but the pseudarthroses so formed, even when modified by J. S. Batchelor's ${ }^{3}$ low subtrochanteric osteotomy, did not confer weight-bearing stability, and a conspicuous limp was usual. Attempts to produce a more formal arthroplasty by interposing fascia or skin between the trimmed femoral head and the prepared surface of the acetabulum were improved upon by $M$. N. Smith-Petersen, ${ }^{4}$ who in 1938 introduced a vitallium mould between the bony surfaces. Though the cup arthroplasty produced a stable hip, it required prolonged postoperative rehabilitation and gave even in the best hands acceptable relief of pain in no more than two out of three patients. ${ }^{5}$ In 1950 the Judet brothers ${ }^{6}$ showed the remarkable success that could be achieved by the prosthetic replacement of the femoral head, but the choice of an unsuitable material and of a short stem giving insufficient fixation to the femur led to the early failure of this particular technique. The more durable long-stemmed metal femoral prostheses of F. R. Thompson ${ }^{7}$ and Austin Moore ${ }^{8}$ proved far more satisfactory and are still widely used when replacement of the femoral head alone is required. They do not, however give, reliable relief from pain when both sides of the hip are diseased.

The possibility of replacing the whole joint, a total hip replacement arthroplasty, has been methodically studied over the last two decades, notably by G. K. McKee in Norwich and by Charnley at Wrightington. McKee and J. WatsonFarrar in 1962 adopted Charnley's suggestion ${ }^{9}$ of using a cold-curing acrylic cement as a grouting agent to distribute the stresses from the metal components evenly over the adjacent bone. In 1966 they were able to report $90 \%$ success in relief of pain in their first fifty patients. ${ }^{10}$ Charnley considered that the stresses arising from frictional resistance in such a metal-to-metal bearing might eventually cause loosening of the prosthesis in the bone. He concentrated on the design of a low-friction arthroplasty, using a small metal femoral head articulating with a plastic acetabular prosthesis. Teflon was first chosen for the plastic component ${ }^{11}$ because of its excellent lubricating properties, but it unfortunately showed poor resistance to mechanical wear and in particulate form caused severe tissue reaction. High-density polyethylene replaced Teflon for the acetabular component in 1962, and it has been used by Charnley and his followers ever since.

Charnley ${ }^{1}$ now reports 379 primary operations done bewteen 1962 and 1965 . The mortality was $2 \cdot 1 \%$, two out of three deaths being from pulmonary embolism. Early evidence of infection occurred in $1.6 \%$, but in a further $2.2 \%$ infection became apparent months or years later. Late mechanical failure occurred at a rate of $1.3 \%$. Of the remaining patients $90 \%$ obtained complete relief of pain and restoration of normal ability to walk. The other $10 \%$ had slight or intermittent pain and though not needing to use a stick walked with a limp. Restoration of movement was not quite so spectacular, though in all cases the range of motion was improved. The average stay in hospital was then four weeks. No elaborate aftercare was needed.

Total hip replacement is now almost a major industry in this country and many surgeons are able to record a similar degree of early success. Reports of transient hypotension after the insertion of acrylic cement ${ }^{12}$ have caused some surgeons to prefer Ring's prosthesis, with which cement is not used, ${ }^{13}$ but it is not so far established that this method can produce such regular and lasting success. Because we do not yet know the outcome of many years' use of these artificial joints, they are still to be employed in younger patients only with great caution and usually only when other aspects of the patient's disability will limit the use to be made of the hip. Osteotomy and arthrodesis are still indicated in the management of patients under the age of 50 .

The greatest threat to the success of a total hip replacement is infection, which will usually require its conversion to a Girdlestone pseudarthrosis. The operation must be carried out only in theatres where a high standard of asepsis can be maintained. The value of Charnley's special clean-air operating enclosure seems likely to be established, and it is among the precautions to be seriously considered in any centre where this type of surgery is to be regularly under- 
taken. Employed with proper care, total hip replacement arthroplasty is now the treatment of choice for many sufferers from hip disease.

1 Charnley, J., Fournal of Bone and foint Surgery, 1972, 54B, 61.

2 Girdlestone, G. R., Proceedings of the Royal Society of Medicine, 1945,

38, 363.
3 Batchelor, J. S., Proceedings of the Royal Society of Medicine, 1945, 38, 689.

Smith-Petersen, M. N., Journal of Bone and Foint Surgery, 1939, 21, 269.

5 Law, W. A., Fournal of Bone and foint Surgery, 1962, 44A, 1497

- Law, W. A., fournal of Bone and foint Surgery, 1962, 44A, 1497.

7 Thompson, F. R., fournal of Bone and foint Surgery, 1954, 36A, 489.

7 Thompson, F. R., Fournal of Bone and foint Surgery, 195

- Charnley, J., fournal of Bone and foint Surgery, 1960, 42B, 28

10 McKee, G. K., and Watson-Farrar, J., fournal of Bone and foint Surgery, 1966, 48B, 245.

11 Charnley, J., Lancet, 1961, 1, 1129.

12 Peebles, D. J., Ellis, R. H., Stride, S. D. K., and Simpson, B. R. J., British Medical fournal, 1972, 1, 349.

1s Ring, P. A., fournal of Bone and foint Surgery, 1968, 50B, 720.

\section{Auditory Inattention}

Patients with certain cerebral lesions may have normal fields of vision, normal hearing in each ear, and normal sensation in the limbs tested individually, and yet when bilateral visual, auditory, painful, or tactile stimuli are presented to the patient simultaneously he may recognize a stimulus only on one side, and consistently so. This phenomenon has variously been termed inattention, ${ }^{1}$ extinction, ${ }^{2}$ suppression, ${ }^{3}$ perceptual rivalry, ${ }^{4}$ or neglect, ${ }^{5}$ preceded by the adjective appropriate to the stimulus tested-for example, visual inattention.

H. Oppenheim ${ }^{6}$ described the phenomenon at the end of the last century. J. Babinski, ${ }^{5}$ before the first world war, extended the concept of unilateral neglect to positive denial of disability, such as denial of hemiplegia, and he called the condition anosognosia. Between 1945 and 1953 inattention or extinction was extensively studied, described, and argued about by M. B. Bender and various associates ${ }^{2} 8$ and by Macdonald Critchley. ${ }^{1} 9$ From their work it appeared that from the strictly practical point of view the condition was usually, though not invariably, a sign of a parietal lobe lesion, and it is of course much easier to demonstrate the sign in patients with lesions of the non-dominant hemisphere, whose speech and ability to comprehend are intact, than when the dominant hemisphere is affected. Many of the earlier conclusions about the localization of the lesion relied either on a clinician's judgement or on post-mortem findings, and in general most attention was paid to visual and tactile inattention. Auditory inattention had, however, been described by Oppenheim, 1 and in more detail by $M$. B. Bender and S. P. Diamond, 1011 and D. Denny-Brown and his colleagues. ${ }^{4}$ Again a lesion localized in the parietal lobe was postulated, not invariably with objective confirmation.

Now K. M. Heilman and E. Valenstein ${ }^{12}$ have described 17 cases showing auditory neglect, all of whom were studied by technetium-99 rectilinear brain scanning. Each patient had had some auditory stimulus presented to each ear individually and been shown not to have loss of auditory acuity. Various stimuli were then presented bilaterally and simultaneously by the simple processes of snapping fingers, jingling coins, or placing a stethoscope in the patient's ears and tapping on the diaphragm. The patients consistently identified the sound on one side only. Ten of the 17 had positive brain scans owing to neoplasm or infarction, and nine of these showed lesions in the right inferior parietal area. One lesion was in the left posterior frontal zone. The patients all showed the other forms of sensory inattention as well.
This is not by any means a new test, but it is interesting to correlate investigation of the phenomenon by modern techniques with the older conclusions about the most usual site of the lesion, sometimes deduced, but not proved. These tests are simple to perform and yet not often carried out. The discovery of any of these forms of inattention or neglect makes one strongly suspect a parietal lobe lesion, even in the absence of other forms of so-called "cortical" sensory disturbance. The phenomenon has been found in lesions at other sites, however, and, though valuable, it should not by itself be considered to be of absolute localizing significance.

1 Critchley, M., Brain, 1949, 72, 538.

2 Bender, M. B., Archives of Neurology and Psychiatry, 1945, 54, 1.

3 Furmanski, A. R., Archives of Neurology and Psychiatry, 1950, 63, 205.

4 Denny-Brown, D., Meyer, J. S., and Horenstein, S., Brain, 1952, 75, 433.

5 Babinski, J., Revue Neurologique, 1914, 22, 845 .

6 Oppenheim, H., Neurologisches Zentralblatt, 1885, 4, 529.

7 Bender, M. B., and Furlow, L. T., Archives of Neurology and Psychiatry, 1945, 53, 29.

${ }^{8}$ Bender, M. B., Fink, M., and Green, M., Archives of Neurology and Psychiatry, 1951, 66, 355.

9 Critchley, M., The Parietal Lobes. London, Arnold, 1953.

10 Bender, M. B., and Diamond, S. P., Brain, 1965, 88, 675.

1 Diamond, S. P., and Bender, M. B., Transactions of the American Neurological Association, 1965, 90, 154.

12 Heilman, K. M., and Valenstein, E., Archives of Neurology, 1972, 26, 32.

\section{Heart Operations Followed Up}

Recently we have become so accustomed to truly dramatic developments in cardiac surgery that it is sometimes hard to believe that it all started only 25 years ago. The publication ${ }^{1}$ by Helen Taussig of long-time observations on the first 1,037 cyanotic patients operated upon by Dr. Blalock and his associates between 1945 and 1951 has therefore not only considerable intrinsic interest but helps to put this remarkable work into perspective.

Apart from patients in whom the diagnosis was in doubt and those who had operations other than a Blalock-Taussig anastomosis, 728 patients with tetralogy of Fallot were treated, with a $10 \%$ surgical mortality, and $81.7 \%$ of them were judged to have had an excellent or good immediate result. Most of the patients were children, the peak in the age distribution curve being between 2 and 5 years. The scatter was wide, however, and there were 17 among those aged under 1 and over 25 years. Mortality was highest under the age of $2(27 \cdot 4 \%)$ but only $6.5-7 \%$ between the ages of 6 and 14 years.

Because patients travelled from far and wide to Baltimore seeking treatment, long-term assessment has not been easy, and Dr. Taussig and her colleagues have gone to great lengths to achieve a 93\% 10-year and an $88 \%$ 15-year follow-up of the 685 cases who left hospital alive two months after their first operation. Year-by-year analysis shows a relatively high mortality rate between 3 and 11 months after operation; thereafter it was remarkably constant. Though 209 patients had second operations within 15 years, the majority because of failure to maintain improvement, 313 were living on their first anastomosis 15 years later. It is of considerable interest that losses in the latter group were at a lower rate than the $30 \%$ surgical mortality combined with the late mortality in the group who had further operations. The results of all types of heart surgery have steadily improved with practice (Blalock's mortality rates fell from $20.3 \%$ in 1945 to $4.7 \%$ in 1951), 